\title{
State-of-Charge Monitoring and Battery Diagnosis of NiCd Cells Using Impedance Spectroscopy
}

\author{
Peter Kurzweil ${ }^{1, *(1)}$ and Wolfgang Scheuerpflug ${ }^{2}$ \\ 1 Electrochemistry Laboratory, University of Applied Sciences (OTH), Kaiser-Wilhelm-Ring 23, 92224 Amberg, \\ Germany \\ 2 Diehl Aerospace GmbH, Donaustraße 120, 90451 Nürnberg, Germany; wolfgang.scheuerpflug@diehl.com \\ * Correspondence: p.kurzweil@oth-aw.de; Tel.: +49-9621-482-3317
}

Received: 14 December 2019; Accepted: 6 January 2020; Published: 9 January 2020

check for updates

\begin{abstract}
With respect to aeronautical applications, the state-of-charge (SOC) and state-of-health $(\mathrm{SOH})$ of rechargeable nickel-cadmium batteries was investigated with the help of the frequency-dependent reactance $\operatorname{Im} \underline{Z}(\omega)$ and the pseudo-capacitance $C(\omega)$ in the frequency range between $1 \mathrm{kHz}$ and $0.1 \mathrm{~Hz}$. The method of SOC monitoring using impedance spectroscopy is evaluated with the example of 1.5-year long-term measurements of commercial devices. A linear correlation between voltage and capacitance is observed as long as overcharge and deep discharge are avoided. Pseudo-charge $Q(\omega)$ $=C(\omega) \cdot U$ at $1 \mathrm{~Hz}$ with respect to the rated capacity is proposed as a reliable $\mathrm{SOH}$ indicator for rapid measurements. The benefit of different evaluation methods and diagram types for impedance data is outlined.
\end{abstract}

Keywords: battery life testing; capacitance; state-of-charge determination; state-of-health; aging; impedance spectroscopy; pseudo-charge

\section{Introduction}

Emergency power supplies in aircrafts require high reliability. After parking for a longer period of time without electric supply, the state-of-charge (SOC) of airplane batteries drops by self-discharge. Scheduled take-offs may be delayed by this. According to the state-of-the-art, the complete procedure of capacity determination lasts several hours. As a costly precaution, freshly charged batteries must be held in stock. With respect to more extended maintenance intervals, a reliable method for fast battery diagnosis is required, which reflects at least the upper SOC range.

Based on preliminary work on SOC determination by impedance spectroscopy [1-7], we studied new and aged batteries. Since the frequency response depends on the cell chemistry, we focused on nickel-cadmium batteries [8-10] in this work. In the following, the significance of the imaginary part of impedance is evaluated with respect to aging time and state-of-charge.

\subsection{State-of-Charge Indicators}

Rated capacity [11] denotes the electric charge $Q_{\mathrm{N}}$, which is stored by a new battery conditions. The actually available capacity $Q(t)$, however, is lower by the already consumed charge $Q_{1}$, and the capacity loss $Q_{\mathrm{L}}$ in the course of aging during the time $t$. Moreover, the capacity $Q_{0}$ of the fully charged battery depends on temperature and previous charge-discharge cycles at given C-rates.

$$
\begin{gathered}
Q(t)=Q_{\mathrm{N}}-Q_{1}-Q_{L}=\alpha \cdot Q_{0}=\alpha \cdot \beta \cdot Q_{\mathrm{N}} \\
\operatorname{SOC}=Q / Q_{0}=\alpha
\end{gathered}
$$

$\alpha$, the state-of-charge (SOC) [12], describes the ratio between the actually momentary available capacity $Q(t)$ and maximum total available capacity $Q_{0}$ at the previous full charge. $\alpha=1(100 \%$ SOC) represents 
the full charge, and $\alpha=0(0 \%$ SOC) is an empty battery. For SOC determination $[13,14]$, voltage measurements were general practice since the 1930s. Since the mid-1970s, impedance spectroscopy [15], coulomb counting [16], bookkeeping methods [17,18], and look-up tables [19] came along, which were complemented by fuzzy logic, Kalman filters, learning algorithms and predictive methods [14], and the analysis of relaxation times [20] over the past decades. The C-rate is defined by the current-capacity ratio. The indication $1 \mathrm{C}$ says that the battery was fully charged or discharged within one hour. $5 \mathrm{C}$ requires $0.2 \mathrm{~h}(12 \mathrm{~min})$.

The state-of-health (SOH) [12] considers the actually available residual capacity in aged batteries $Q_{0}$ with regard to the nominal rated capacity $Q_{\mathrm{N}}$ of the new battery.

$$
\mathrm{SOH}=Q_{0} / Q_{\mathrm{N}}=\beta
$$

\subsection{Aging Phenomena}

Aging starts immediately after the battery has left the fabrication facilities. The degradation rate depends on cycling stress, temperature, charging method, overcharge, and deep-discharge. Some aging phenomena are reversible, but most are irreversible. Calendar aging during storage with time happens in the battery at rest at any temperature and state-of-charge, independently of the power load. Cyclic aging depends on current (C-rate), temperature, depth-of-discharge, power demand, and the load profile. Repeated charge-discharge events at $0 \%-20 \%$ SOC and $80 \%-100 \%$ SOC are more harmful to the battery than continuous operation at medium SOC levels.

The memory effect [21] or lazy battery effect is a special type of aging phenomenon with rechargeable nickel-cadmium (NiCd) chemistry that causes the battery to hold less charge (Figure 1). The battery gradually loses its maximum energy capacity when it is repeatedly recharged after being only partially discharged [22]. The battery seems to remember the previous state of charge, and causes an undesired early voltage drop when charged again. Due to crystal formation at the anode, the stored energy becomes available only at a lower voltage than before. Unfortunately, the memory effect is exceedingly difficult to reproduce in model experiments. In modern NiCd batteries, the resulting loss of capacity is partly compensated by a discharge reserve. The memory effect can be repaired by a complete charge-discharge cycle, which recovers the original capacity (except for calendar and cycle aging).

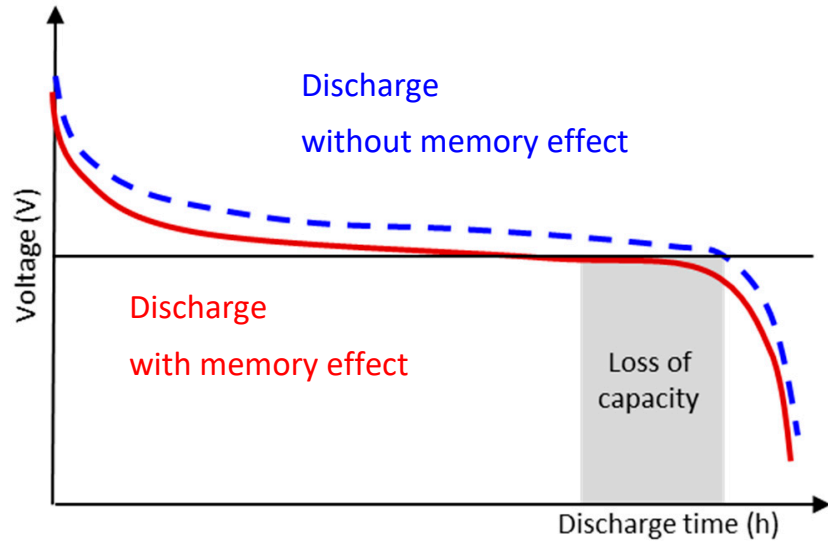

(a)

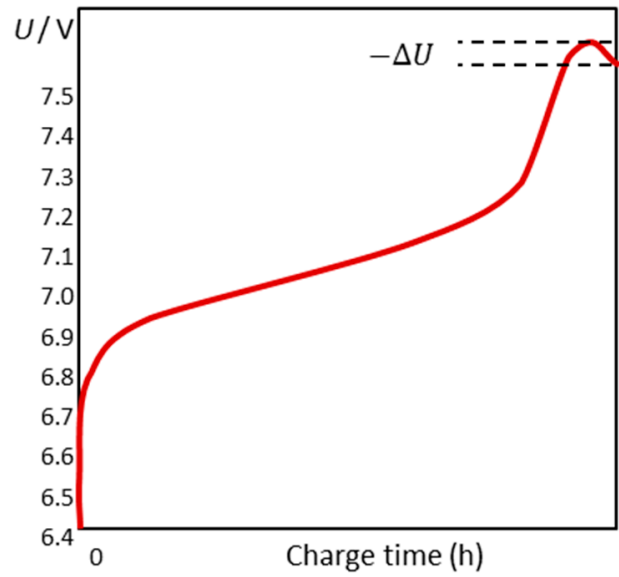

(b)

Figure 1. (a) Qualitative discharge characteristics of a nickel-cadmium battery suffering the memory effect. (b) End-of-charge determination by minus-delta-U cutoff. $U=$ voltage in volts.

The voltage cutout is a widely used to prevent overcharge. The NiCd battery is continuously charged until the voltage drops by $0.01-0.02 \mathrm{~V}$ per cell although energy is supplied (Figure $1 \mathrm{~b}$ ). 


\subsection{Impedance Spectroscopy}

The observed $a c$ resistance of every electrochemical cell is caused by the electrolyte resistance and the kinetic inhibitions of the electrode processes, which act like non-ideal resistors and capacitances. With electrochemical impedance spectroscopy (EIS) [23], a periodically changing voltage (at constant cell voltage) or current excitation signal (at constant discharge current), respectively, is applied to the battery. The resulting phase shift $\phi$ between input signal and cell response is recorded frequency by frequency. The amplitude of the usually sinusoidal input signal must be small, so that the steady-state condition of the cell is not disturbed.

Commercial frequency response analyzers (FRA) deliver the frequency-dependent complex impedance $\underline{Z}(\mathrm{j} \omega)$ or admittance $\underline{Y}(\mathrm{j} \omega)$ in various mathematical formats, with respect to angular frequency $\omega=2 \pi f$, resistance $R=\operatorname{Re} \underline{Z}$ (real part of impedance), reactance $X=\operatorname{Im} \underline{Z}$ (imaginary part of impedance), modulus $Z=|\underline{Z}|$, and phase shift $\phi=\phi_{U}-\phi_{I}$ between $a c$ voltage and $a c$ current.

$$
\begin{gathered}
\underline{Z}(\mathrm{j} \omega)=\frac{\underline{U}(\mathrm{j} \omega)}{\underline{I}(\mathrm{j} \omega)}=\operatorname{Re} \underline{Z}(\mathrm{j} \omega)+\mathrm{j} \operatorname{Im} \underline{Z}(\mathrm{j} \omega)=|\underline{Z}(\mathrm{j} \omega)| \cdot e^{\mathrm{j} \varphi}=|\underline{Z}(\mathrm{j} \omega)| \cdot[\cos \varphi+\mathrm{j} \sin \varphi] \\
|\underline{Z}(\mathrm{j} \omega)|=\frac{U_{\text {eff }}(\mathrm{j} \omega)}{I_{\text {eff }}(\mathrm{j} \omega)}=\sqrt{(\operatorname{Re} \underline{Z}(\mathrm{j} \omega))^{2}+(\operatorname{Im} \underline{Z}(\mathrm{j} \omega))^{2}} \\
\varphi(\mathrm{j} \omega)=\arctan \frac{\operatorname{Im} \underline{Z}(\mathrm{j} \omega)}{\operatorname{Re} \underline{Z}(\mathrm{j} \omega)}=\operatorname{sgn}[\operatorname{Im} \underline{Z}(\mathrm{j} \omega)] \cdot \arccos \frac{\operatorname{Re} \underline{Z}(\mathrm{j} \omega)}{|\underline{Z}(\mathrm{j} \omega)|} \\
\underline{Y}(\mathrm{j} \omega)=\operatorname{Re} \underline{Y}(\mathrm{j} \omega)+\mathrm{j} \operatorname{Im} \underline{Y}(\mathrm{j} \omega)=\frac{1}{\underline{Z}(\mathrm{j} \omega)}=\frac{\operatorname{Re} \underline{Z}(\mathrm{j} \omega)}{|\underline{Z}(\mathrm{j} \omega)|^{2}}+\mathrm{j} \frac{-\operatorname{Im} \underline{Z}(\mathrm{j} \omega)}{|\underline{Z}(\mathrm{j} \omega)|^{2}}
\end{gathered}
$$

Figure 2 illustrates these quantities in the complex plane and frequency domain.

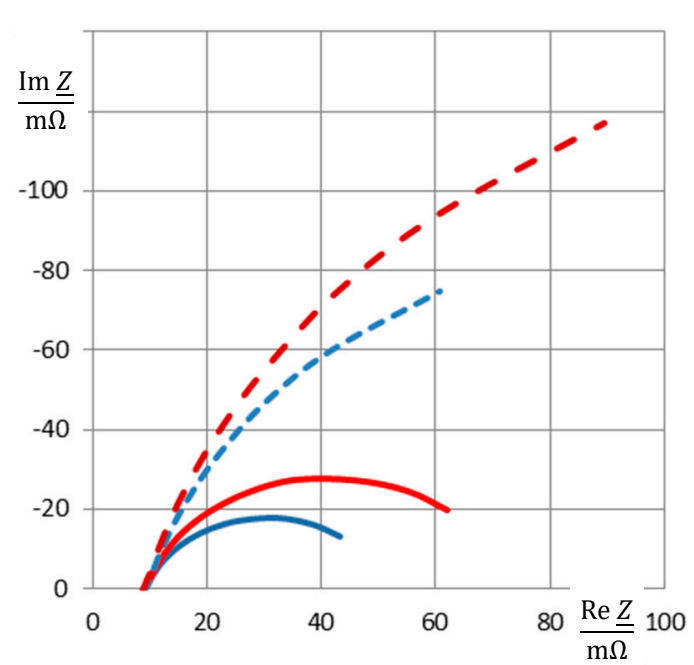

(a)

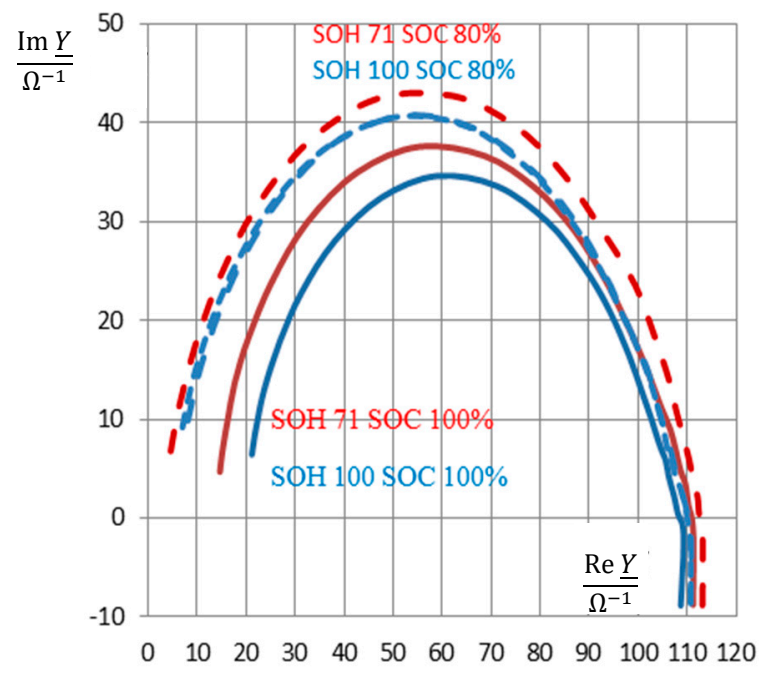

(b)

Figure 2. Cont. 


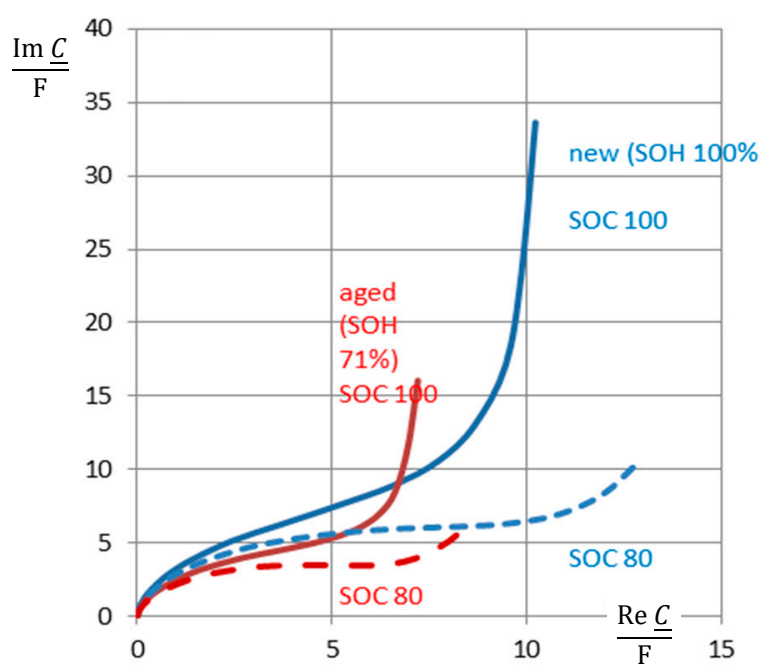

(c)

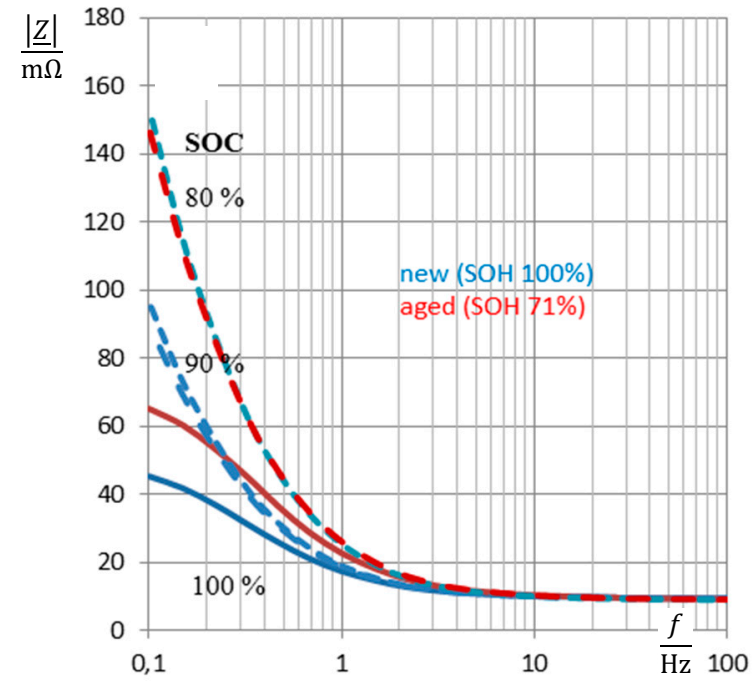

(d)

Figure 2. Impedance spectra of a nickel-cadmium (NiCd) battery (cell \#5, new: State-of-health (SOH) $100 \%=1.7 \mathrm{Ah}$, aged: $\mathrm{SOH} 71 \%=1.21 \mathrm{Ah}$ ) at full charge (state-of-charge $(\mathrm{SOC})=100 \%$, solid line) and $80 \%$ state-of-charge (dashed): (a) complex plane plot of impedance $\underline{Z}$, so-called Nyquist plot, (b) admittance $\underline{Y}=1 / \underline{Z}$ in the complex plane, (c) complex capacitance $\underline{C}=\underline{Y} /(\mathrm{j} \omega)$, (d) frequency response of modulus $|\underline{Z}|(\omega)$, part of Bode diagram. Reactance $\operatorname{Im} \underline{Z}$, susceptance $\operatorname{Im} \underline{Y}$, and pseudocapacitance $\operatorname{Re}$ $\underline{C}$ reflect the state-of-charge more clearly than the ohmic resistance $\operatorname{Re} Z$, conductance $\operatorname{Im} Y$, and the phase angle $\phi$ (not shown here).

\subsection{Capacitance and Time Constant}

We added the pseudo-capacitance $C(\omega)[1,24,25]$ to the above list, as a unique measure for the activity of the electrode/electrolyte interface, and as a qualitative indicator for the state-of-charge of the battery. The frequency response of the real part of complex capacitance $\underline{C}=\underline{Y} /(\mathrm{j} \omega)$ is given by Equation (4).

$$
C(\omega)=\frac{\mathrm{d} Q}{\mathrm{~d} U}=\operatorname{Re} \underline{C}(\mathrm{j} \omega)=\frac{\operatorname{Im} \underline{Y}(\mathrm{j} \omega)}{\mathrm{j} \omega}=\frac{-\operatorname{Im} \underline{Z}(\mathrm{j} \omega)}{\omega \cdot|\underline{Z}(\mathrm{j} \omega)|^{2}}
$$

At high frequencies $(\omega \rightarrow \infty)$, pseudo-capacitance tends to the geometric double-layer capacitance $C_{\mathrm{D}}$ of the electrode/electrolyte interface. The ohmic resistance of the electrolyte solution, $R_{\mathrm{e}}=\operatorname{Re} \underline{Z}(\omega$ $\rightarrow \infty$ ), is found as the intersection of the complex plane plot with the real axis.

$$
C_{\mathrm{D}}=\lim _{\omega \rightarrow \infty} C(\omega)=\lim _{\omega \rightarrow \infty} \frac{-\operatorname{Im} \underline{Z}(\omega)}{\omega \cdot\left[\left[\operatorname{Re} \underline{Z}(\omega)-R_{\mathrm{e}}\right]^{2}+[\operatorname{Im} \underline{Z}(\omega)]^{2}\right]} \approx \frac{-1}{\omega \cdot \operatorname{Im} \underline{Z}(\omega)}
$$

The diagram of frequency-dependent capacitance $C(\omega)$ versus resistance $R$ is useful for the direct comparison of battery capacities (see Section 3.5). The approximation in Equation (5) holds only for high frequencies, when the polarization resistance of the battery is negligible.

We think that the classification of aging phenomena is simplified by the apparent time constant of the charge-transfer reaction [26]. As a useful quantity for the comparison of new (at time $t=0$ ) and aged batteries at any time $t$, we will consider below the relative growth of electrolyte resistance (at a given high frequency, e.g., $1 \mathrm{kHz}$ ) and the loss of capacitance (at a low frequency, e.g., $0.1 \mathrm{~Hz}$ ).

$$
\tau(t)=\frac{R(t) \cdot C(t)}{R_{0} C_{0}}
$$




\section{Experimental Setup}

In the course of a long time, with tests under real conditions as in an airplane, six NiCd battery packs were kept at a state-of-charge of $100 \%$ by trickle charge in order to balance self-discharge. With cycling, the packs were charged and discharged at a rate of $\mathrm{C} / 2$ between $100 \%$ SOC $(7.5 \mathrm{~V})$ to $80 \%$ SOC (6.0 V), separated by a rest period of $15 \mathrm{~min}$, as shown in Figure 3 and Table 1. The ambient temperature was $50^{\circ} \mathrm{C}$ during aging. Impedance spectra were measured at $25^{\circ} \mathrm{C}$ after every 400 cycles, because (i) this temperature change is close to the practical application in the airplane, and (ii) helps to standardize the temperature-dependence of impedance, which affects the electrolyte resistance and the polarization resistance and the electrochemical reactions in a different way.

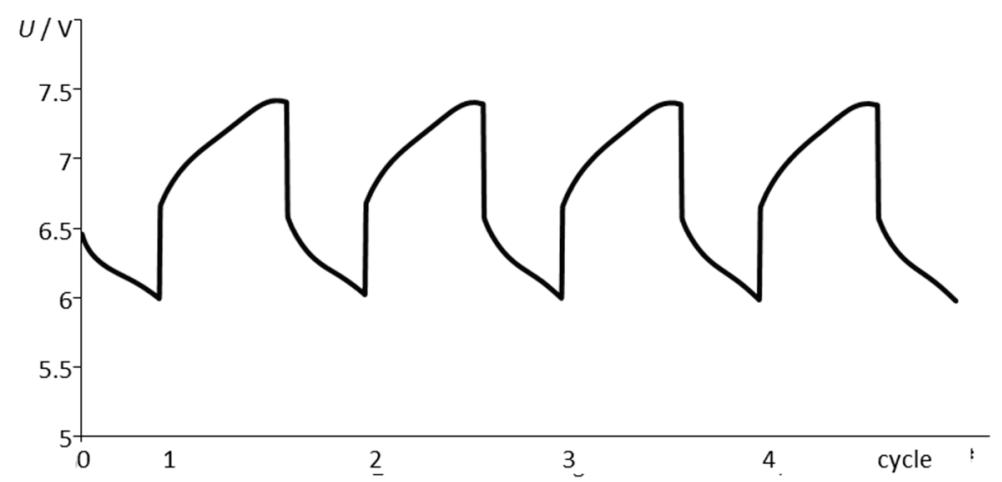

Figure 3. Voltage during continuous cycle testing at $50{ }^{\circ} \mathrm{C}(\mathrm{NiCd}, 1.7 \mathrm{Ah}, 0.5 \mathrm{C})$ for 1200 cycles.

Table 1. Overview of experiments.

\begin{tabular}{|c|c|c|c|c|}
\hline Test Method & $\begin{array}{l}\text { Battery Pack: } \\
\text { 7.5 V, 1.7 Ah, } \\
5 \text { Single Cells }\end{array}$ & $\begin{array}{l}\text { A. Cycling } \\
\text { (SOC) at } 50^{\circ} \mathrm{C}\end{array}$ & $\begin{array}{c}\text { B. Impedance } \\
\text { Measurements During } \\
\text { Discharge (SOC } 1 \rightarrow 0.7) \\
\text { After 400, 800, } 1200 \text { Cycles }\end{array}$ & $\begin{array}{l}\text { C. Capacity After } \\
\text { Full 0.5C Charge } \\
\text { (Ah Counting) }\end{array}$ \\
\hline 1 Full discharge & $\begin{array}{l}\text { (a) old (\#1) } \\
\text { (b) new (\#4) }\end{array}$ & $\begin{array}{c}1 \mathrm{C}(1 \rightarrow 0) \\
0.5 \mathrm{C}(1 \rightarrow 0)\end{array}$ & by $2 \%$ voltage steps & $\begin{array}{c}\text { at cycle } 400,800, \\
\text { and } 1200\end{array}$ \\
\hline 2 Partial discharge & $\begin{array}{l}\text { (a) old (\#2) } \\
\text { (b) new (\#5) }\end{array}$ & $\begin{array}{c}1 \mathrm{C}(1 \rightarrow 0.8) \\
0.5 \mathrm{C}(1 \rightarrow 0.8)\end{array}$ & by 0.19 Ah steps & $\begin{array}{l}\text { at cycle } 400,800, \\
\text { and } 1200\end{array}$ \\
\hline 3 Partial discharge & $\begin{array}{l}\text { (a) old (\#3) } \\
\text { (b) new (\#6) }\end{array}$ & $\begin{array}{l}0.1 \mathrm{C}(1 \rightarrow 0.8) \\
0.5 \mathrm{C}(1 \rightarrow 0.8)\end{array}$ & by $2 \%$ voltage steps & $\begin{array}{c}\text { at cycle } 400,800 \\
\text { and } 1200\end{array}$ \\
\hline
\end{tabular}

With respect to the investigation of the memory effect, three types of experiments were defined:

1. Successive discharge. Pack \#1 (fabricated in 2017) was cycled between $\mathrm{SOC}=100 \%$ and $\mathrm{SOC}=$ $0 \%$ with $1 \mathrm{C}$ rate. Pack \#4 (2018) was cycled between SOC $=100 \%$ and SOC $=80 \%$ at $0.5 \mathrm{C}$ rate. After every 400 cycles, the batteries were fully charged and then successively discharged by $2 \%$ steps, each characterized by impedance spectroscopy, until SOC $=70 \%$ was reached. Capacity was measured at the end of the endurance test, so that no memory effect was eliminated.

2. Rapid test. Pack \#2 (2017) was cycled between SOC $=100 \%$ and SOC $=80 \%$ at $1 \mathrm{C}$ rate, and pack \#5 of 2018 suffered at $0.5 \mathrm{C}$. Every 400 cycles the batteries received (i) full charge, (ii) impedance measurement, (iii) discharge by 0.19 Ah, (iv) again impedance measurement, and (v) capacity measurement by ampere-hour counting. The memory effect was studied between successive tests.

3. Extensive test. Pack \#3 (2017) was cycled between SOC $=100 \%$ and SOC $=80 \%$ at $0.1 \mathrm{C}$ rate and pack \#6 (of 2018) at 0.5C. The analysis combined the above methods: (i) full charge, (ii) successive discharge by $2 \%$ and impedance measurement, until SOC $=70 \%$ was reached, (iii) full charge, and (iv) capacity determination by ampere-hour counting. The loss of capacity was studied for a large number of charge-discharge cycles. 


\section{Results and Discussion}

\subsection{State-of-Charge Monitoring}

The stored residual electric charge $Q$ (capacity) of a battery is expected to correlate with the pseudo-capacitance according to the definition $C=\mathrm{d} Q / \mathrm{d} U$. The pseudo-capacitance, according to Equation (4), is coined by the reactance, therefore the imaginary part of impedance is expected to show the state-of-charge as well. Unfortunately, we found no linear relationship between state-of-charge and capacity (Figure 4). The reactance at $0.1 \mathrm{~Hz}$ drops linearly between $80 \%$ and $20 \%$ SOC, whereas the edges at high and low SOC do not obey the trend.

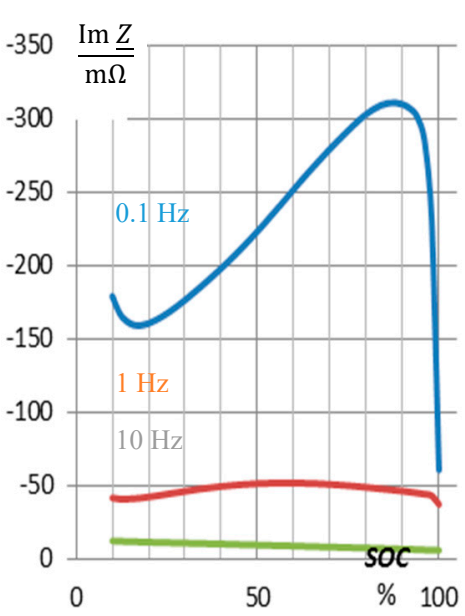

(a)

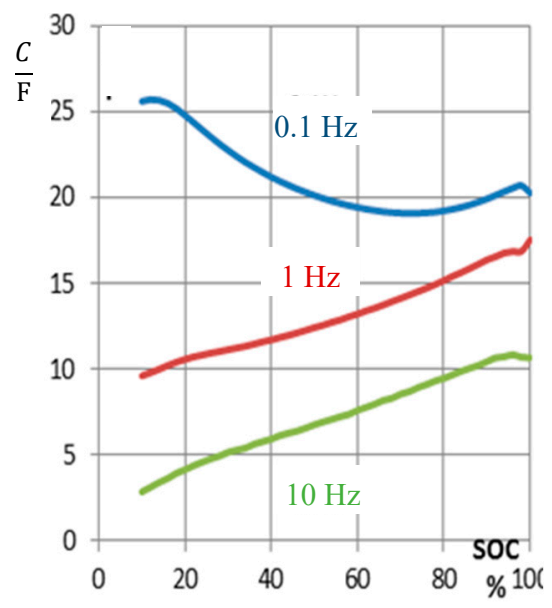

(b)

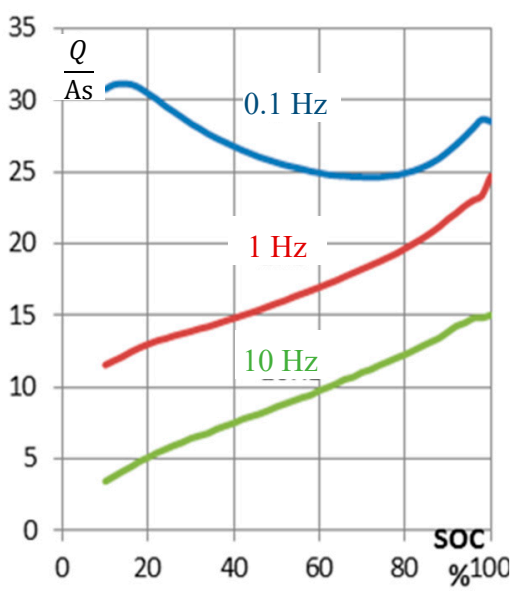

(c)

Figure 4. SOC monitoring by impedance spectroscopy of a used NiCd battery (cell 5 of pack \#3 of 2017). (a) Reactance $X=\operatorname{Im} \underline{Z}$ at different frequencies versus state-of-charge. (b) Pseudo-capacitance $C$ and (c) calculated residual electric pseudo-charge $Q(t)=C U(t)$ at the momentary voltage $U$ (SOC).

The absolute value of reactance $\operatorname{Im} \underline{Z}(1 \mathrm{~Hz})$ shows a maximum around $65 \%$ SOC. In practice, $\operatorname{Im} \underline{Z}(10 \mathrm{~Hz})$ shows a linear trend in the full SOC window. Figure 4 proves that capacitance $C(\omega)$ is a proper measure of the actual battery capacity. Low frequencies are useful for capacity determination.

As well, the pseudo-charge $Q=C \cdot U$ resolves the SOC characteristics more clearly than the imaginary part of impedance. As a compromise, between high signal level (at low frequencies) and linearity (at high frequencies), the imaginary part at $1 \mathrm{~Hz}$ might be appropriate for use in the airplane application, because low charge states are usually not reached in normal use.

\subsection{Reactance during Aging and the Memory Effect}

In long-term tests, all NiCd packs were aged by 1200 cycles. Impedance was recorded every 400 cycles. After 800 and 1200 cycles, respectively, the cells were refreshed in order to eliminate the memory effect.

Figure 5 a compiles the reactance at $1 \mathrm{~Hz}$ versus the real state-of-charge, which was defined by ampere-hour counting. During aging, reactance drops due to the loss of available capacity (100\% to $80 \% \mathrm{SOH}$ ). At the 800 th cycle, $76 \% \mathrm{SOH}$ is reached. The memory effect is eliminated by a single deep-discharge and the successive full charge. Indeed, capacity improves again to 91\% SOH. After 1200 cycles, $97 \% \mathrm{SOH}$ is restored and $77 \% \mathrm{SOH}$ without removal of the memory effect. 


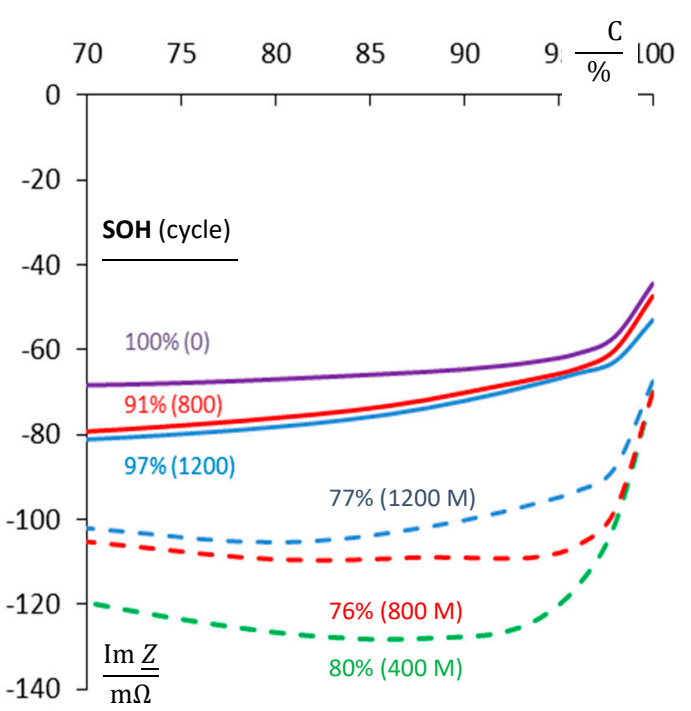

(a)

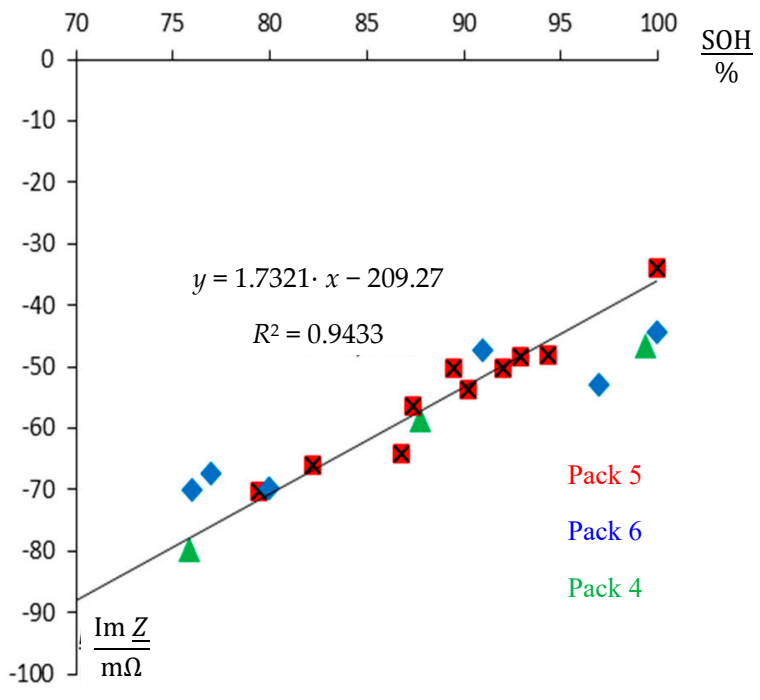

(c)

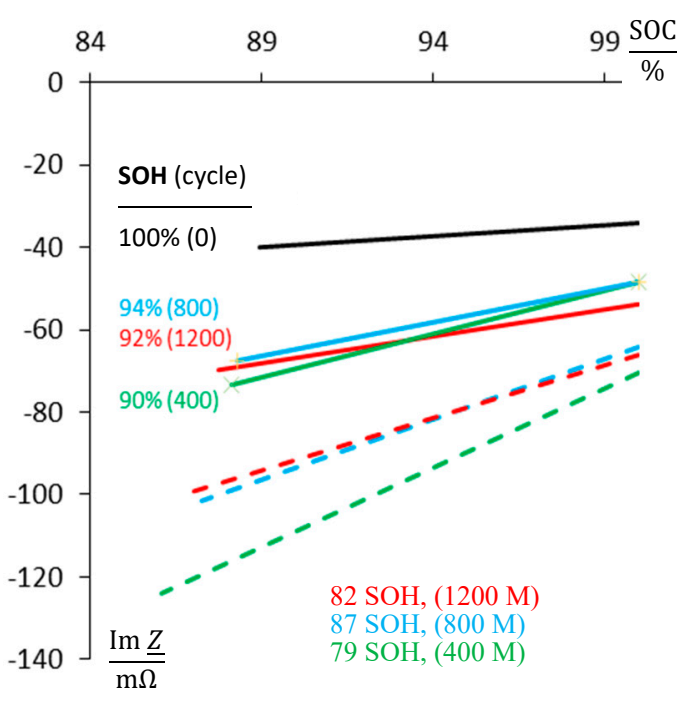

(b)

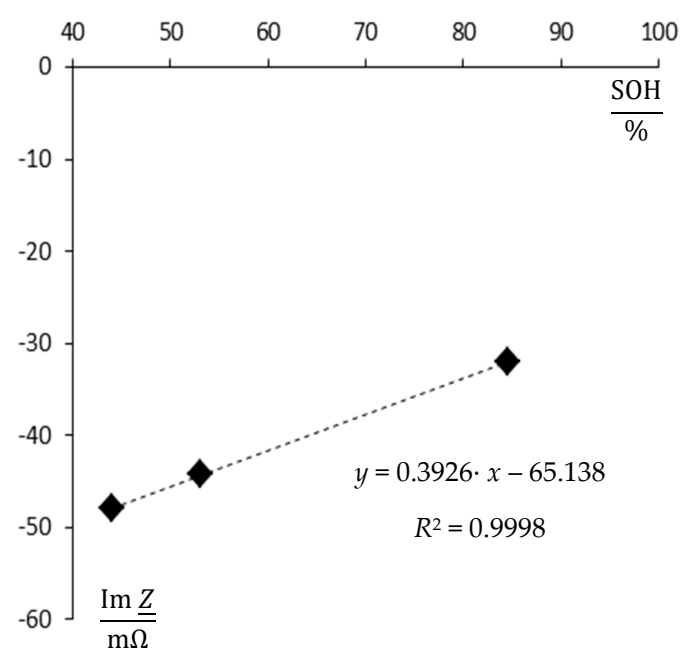

(d)

Figure 5. State-of-health monitoring ( $\mathrm{SOH}$ ) by impedance spectroscopy of NiCd batteries. (a) Reactance $\operatorname{Im} \underline{Z}(1 \mathrm{~Hz})$ during 1200 charge-discharge cycles (cell of new pack $\# 6, \mathrm{C} / 2,50^{\circ} \mathrm{C}$ ). (b) Rapid method with $0.19 \mathrm{mAh}$ discharge and capacity measurement by ampere-hour counting (cell of new pack \#5). (c) Im $\underline{Z}(1 \mathrm{~Hz})$ of fully charged battery packs versus SOH. (d) Cell 5 of pack \#1 after 400 pre-cycles. The state-of-health $\mathrm{SOH}=Q_{0} / Q_{\mathrm{N}}$ (ratio of actual and rated available capacity $Q$ ) correlates quite well with the reactance $\operatorname{Im} \underline{Z}$.

The rapid method (Section 2, Figure $5 \mathrm{~b}$ ) considers the difference between the full battery, and the state-of-charge after discharge of exactly $190 \mathrm{mAh}$ (independent of SOH). The battery was fully discharged after 400, 800, and 1200 cycles. Obviously, the imaginary part of impedance reflects the state-of-health (capacity) during aging. Again, the memory effect can be eliminated by a single deep-discharge and a full charge and the reactance $\operatorname{Im~} Z(1 \mathrm{~Hz})$ displays the real state-of-charge. The results of battery packs \#1 and \#4 are qualitatively identical with packs \#5 and \#6. The 'old' packs \#2 and \#3 were handled in the same way as the 'new' packs \#5 and \#6 except for the changed C-rate, respectively. However, due to previous history with extended dwell times under overcharge, the impedance and aging status do not clearly correlate. 
In Figure $5 c$, the reactance, $\operatorname{Im} \underline{Z}(1 \mathrm{~Hz})$, of three fully charged NiCd packs is compared at different aging states, including and excluding the memory effect. According to the residual capacity between $100 \%$ and $76 \% \mathrm{SOH}$, reactance lies between $-40 \mathrm{~m} \Omega$ and $-80 \mathrm{~m} \Omega$. Low capacity correlates with highly negative reactance. This relation holds even if the memory effect is taken into account. Different battery packs show the same trend in the same order of magnitude.

In Figure 5d, the old battery pack \#1, which suffered from 400 charge-deep discharge cycles before the impedance tests, shows the most serious loss in capacity. After 1200 cycles of the test procedure, residual capacity drops to $44 \% \mathrm{SOH}$ (including memory effect), and $53 \% \mathrm{SOH}$ (after refresh of the memory effect), respectively. Again, the reactance shows the state-of-health.

\subsection{Capacitance as an Aging Indicator}

Pseudo-capacitance $C(\omega)$ at different frequencies was investigated at different cells between beginning of life $(\mathrm{BoL})$ and end of life $(\mathrm{EoL}, \mathrm{SOH}=71 \%)$ at state-of-charge values between $70 \%$ and 100\%. In Figure 6, capacitance displays the state-of-health for the charged batteries between the rated voltage $U_{0}$ and $0.9 U_{0}$. Pseudo-capacitance at $0.1 \mathrm{~Hz}$ shows the difference in the $\mathrm{SOH}$ of new and aged batteries more clearly than the measurement at $0.1 \mathrm{~Hz}$. C calculated by Equation (4) contains the internal resistance of the battery, whereas the approximation $C_{D}$ requires a higher frequency to give a reliable correlation with $\mathrm{SOH}$.

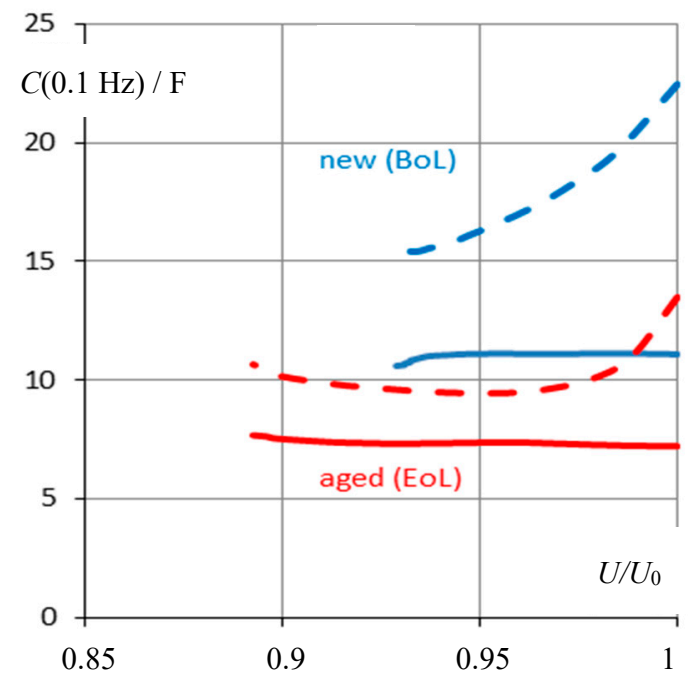

(a)

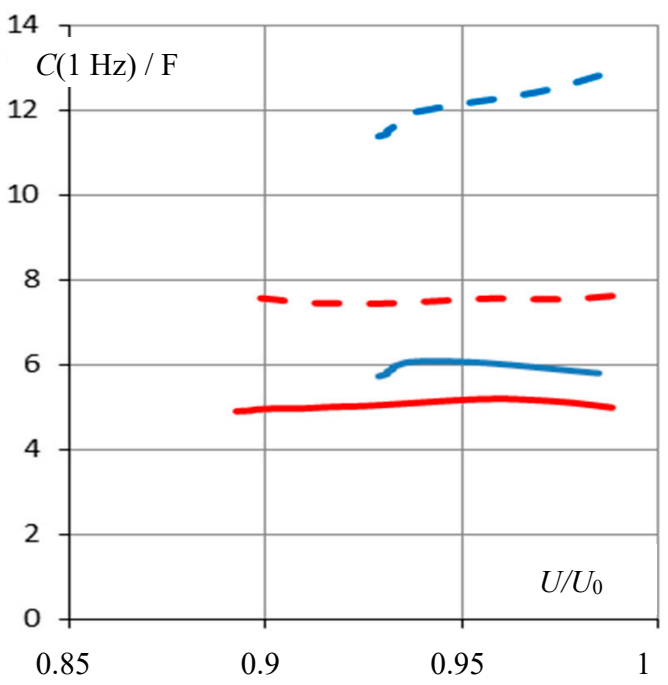

(b)

Figure 6. Capacitance-based state-of-health monitoring with respect to terminal voltage $U / U_{0}$ at (a) $0.1 \mathrm{~Hz}$ and $(\mathbf{b}) 1 \mathrm{~Hz}$. BoL = beginning of life (1.7 Ah), EoL = end of life (1.2 Ah) of cell \#5 of pack \#6. Solid: $C=\operatorname{Im} \underline{Y} /(\mathrm{j} \omega)$, according to Equation (4). Dashed: Approximation $C_{\mathrm{D}}=C(\omega \rightarrow \infty)$.

In any case, capacitance allows distinguishing between full charge and partial charge new and aged batteries, whereas the message at low state-of-charge is less reliable.

\subsection{Pseudo-Charge as a SOH Indicator}

Pseudo-charge, $Q(\omega)=C(\omega) / U$, which was calculated by the measured capacitance $C$ and the momentary cell voltage $U$, correlates more obviously with the state-of-charge along the battery life. For the old battery pack \#6 with respect to the new battery, Figure 7 compiles the relative pseudo-charge at different state-of-charge values. 


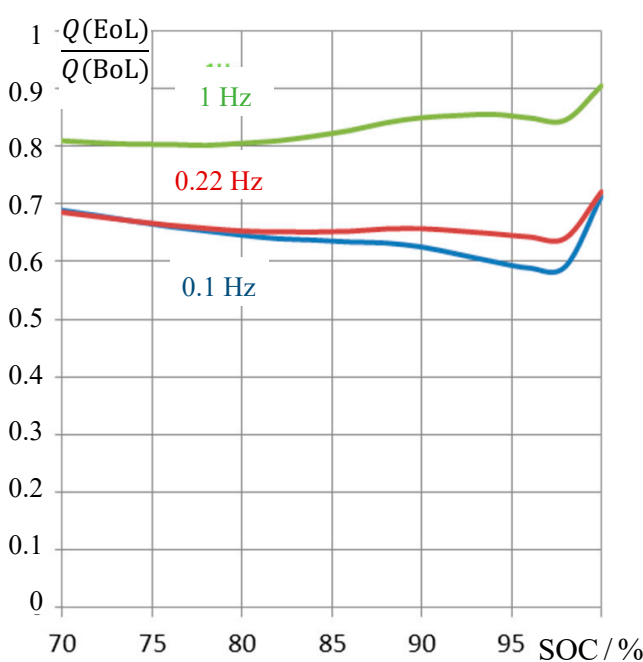

(a)

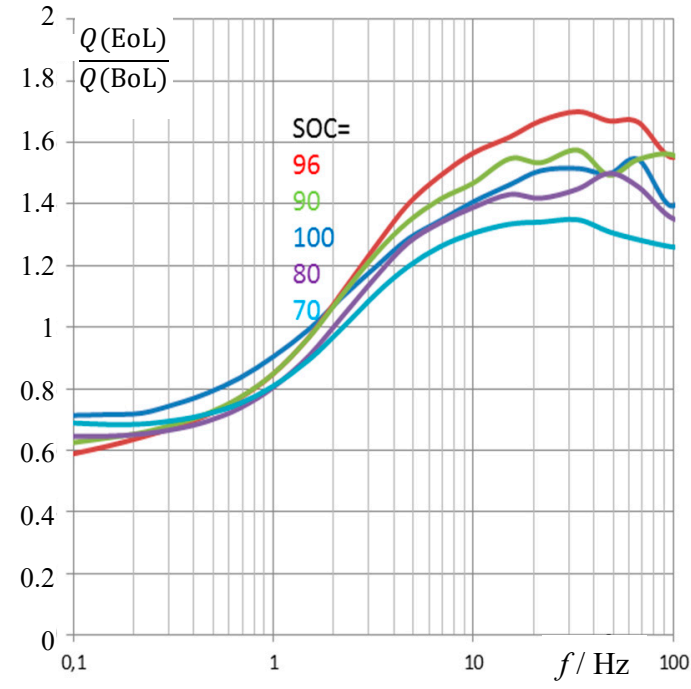

(b)

Figure 7. Aging study. Relative pseudo-charge $Q(\omega)=C(\omega) \cdot U(\mathrm{SOC})$ of an aged 1.7 Ah battery (pack \#6, $\mathrm{EoL}=$ end of life) with regard to the new battery ( $\mathrm{BoL}=$ beginning of life). (a) Impedance measurements at selected frequencies versus the actual state-of-charge $S O C=Q / Q_{0}$ received by genuine Ah counting. (b) Frequency response of relative pseudo-charge, which is determined by the internal resistance of the battery below $1 \mathrm{~Hz}$, and the surface capacitance above $1 \mathrm{~Hz}$.

It becomes obvious that the impedance-based pseudo-charge correlates both with the actual Ah-based state-of-charge SOC between 70\% and $96 \%$. The fully charged battery (SOC $=100 \%$ ) creates an outlier, because of the overcharge phenomenon that distorts the impedance-based capacitance measurement by parasitic electrochemical reactions. As an alternative to Figure 7, the relative loss of charge between new and old batteries can be drawn (i.e., $((Q(\mathrm{EoL})-Q(\mathrm{BoL})) / Q(\mathrm{BoL}))$, which shows the same trend in the reverse direction. Useful frequencies for practical $\mathrm{SOH}$ determination lie below $1 \mathrm{~Hz}$ or below $100 \mathrm{~Hz}$ whether or not the internal resistance of the battery is considered as a proper aging criterion with calculating the pseudo-capacitance, $C(\omega)=\operatorname{Re} \underline{C}$, according to Equation (5). Above $500 \mathrm{~Hz}$, the spiral roll of the cell generates inductive impedance values, which are not useful for state-of-charge determination.

\subsection{Separation of $S O C$ and $\mathrm{SOH}$}

For the comparison of old and new batteries after a given operation time $t$, the pseudo-charge $Q$ is normalized into a range between 0 and 1 , which unlinks the $\mathrm{SOC}$ from the $\mathrm{SOH}$.

$$
Q_{\mathrm{n}}(\omega, t)=\frac{Q(\omega, t)}{Q_{\mathrm{N}}}=\frac{C(\omega, t) / U(t)}{C(\omega, 0) / U_{0}}
$$

$Q_{\mathrm{N}}$ is the rated capacity of the new battery $(\mathrm{SOH}=1, \mathrm{SOC}=1) \cdot Q_{0}$ is the residual capacity of the aged battery $(\mathrm{SOC}=1, \mathrm{SOH}<1) . U_{0}$ is the rated voltage and $U(t)$ is the momentary cell voltage.

The normalized pseudo-charge correlates excellently with the real state-of-charge, which was determined by ampere-hour counting (Figure 8). Advantageously, $Q(1 \mathrm{~Hz})$ is determined very quickly. 


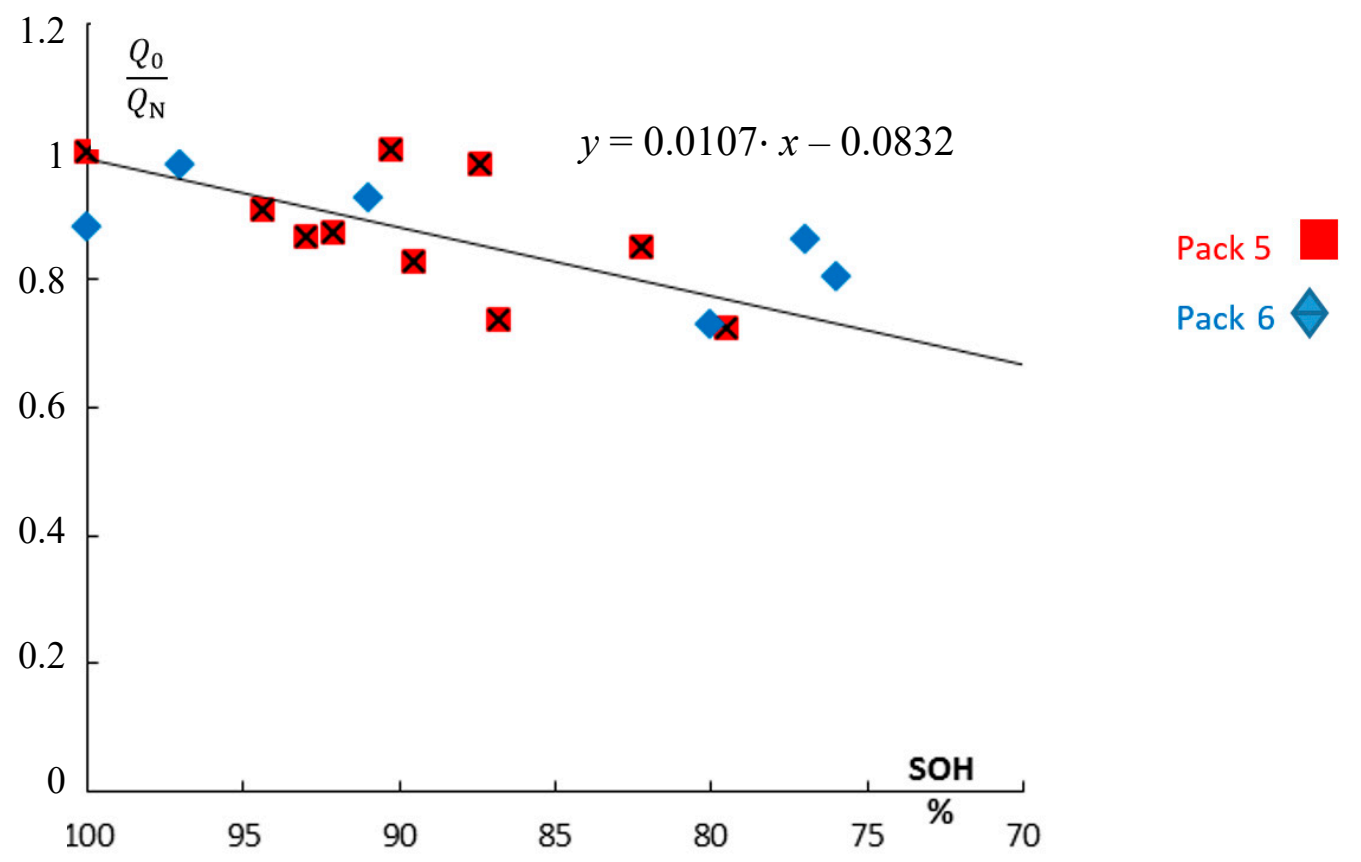

Figure 8. The impact of aging. Ratio of the available electric pseudo-charge $Q_{0}(t)$ of used NiCd batteries with respect to the rated value of the new battery $Q_{N}$ (pack \#5 and pack \#6). Data are taken from Figure 5. Impedance-based pseudo-charge $Q_{0}=C(1 \mathrm{~Hz}) U$ (divided by the rated capacity $Q_{\mathrm{N}}$ ) correlates well with the true $\mathrm{SOH}$ values from Ah measurements.

\subsection{Impedance-Based Aging Indicators}

Diagrams of capacitance versus resistance $C(R)$ have been used for the characterization of supercapacitors, whereby the rated capacitance is reached at low frequencies [1]. Aging generates a growing resistance and a loss of pseudo-capacitance. In Figure 9, however, a constant value of $d c$ pseudo-capacitance is not quickly reached with $\mathrm{NiCd}$ batteries at frequencies down to $0.1 \mathrm{~Hz}$. Especially at low SOC, aged batteries show a less steep slope $\Delta C / \Delta R$ compared with new cells. In any case, the $C(R)$ diagram estimates the extent of aging quickly. We propose this diagram for $\mathrm{SOH}$ monitoring.
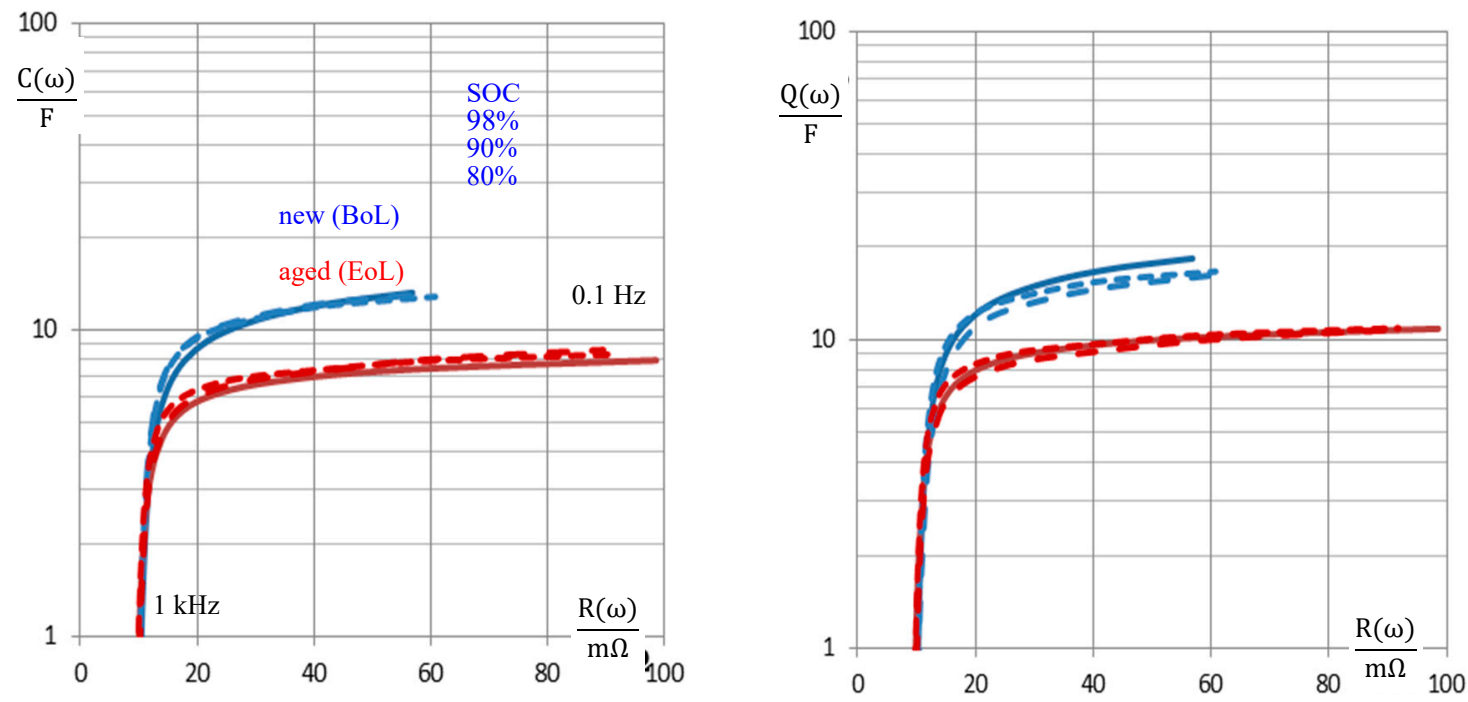

Figure 9. Aging characteristics of NiCd cell \#5 of pack \#6 (new: $1.7 \mathrm{Ah}$, aged: $1.3 \mathrm{Ah}, \mathrm{SOH}=76 \%$ ) in the plot of pseudo-capacitance $C(\omega)$ and pseudo-charge $Q(\omega)=C(\omega) U$ versus the internal resistance (real part of impedance). $U(\mathrm{SOC})=$ actual cell voltage at the time of measurement. 
The reactance (imaginary part of impedance) versus SOC shows a local maximum (Figure 10). This quantity is therefore less useful for $\mathrm{SOH}$ determinations. In contrast to that, relative pseudo-capacitance $C / C_{0}$ increases with SOC the same way as cell voltage $U / U_{0}$ does (Figure 10). This proves why we suggest using capacitance for impedance-based SOC determination.

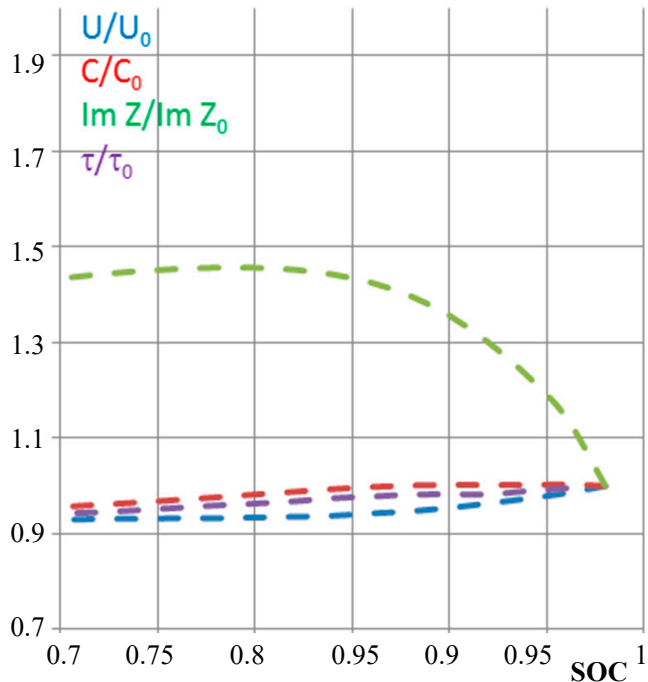

(a)

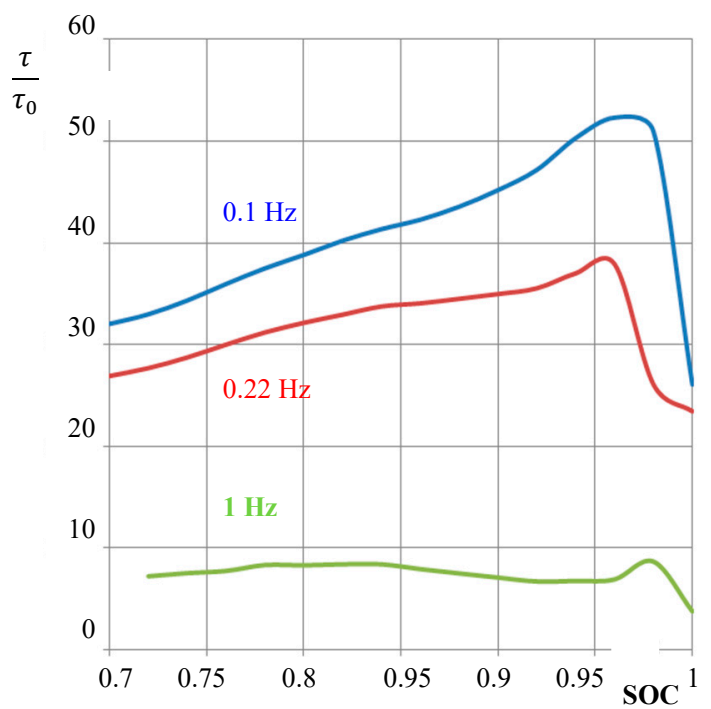

(b)

Figure 10. Aging characteristics of a NiCd battery (cell \#5 of pack \#6). (a) Different normalized state-of-charge quantities with respect to voltage $U / U_{0}$, pseudo-capacitance $C / C_{0}$ at $0.22 \mathrm{~Hz}$, imaginary part of impedance at $0.22 \mathrm{~Hz}$, and relative time constant $\tau / \tau_{0}$ at $0.22 \mathrm{~Hz}$ against the actual state-of-charge received from Ah counting. (b) Relative time constant between the old battery $\tau=R(1 \mathrm{kHz}) \cdot \mathrm{C}(0.1 \mathrm{~Hz})$ and the new battery $\tau_{0}$ at different frequencies according to Equation (6).

The relative time constant $\tau$ according to Equation (5) was determined by the pseudo-capacitance at $0.1 \mathrm{~Hz}$. With this, new and aged batteries can qualitatively be distinguished by a single quantity. A large value of $\tau / \tau_{0}$ means that the aged battery suffers from high electrolyte resistance and low interfacial capacitance.

\section{Conclusions}

For NiCd batteries used in airplanes at SOC values above $70 \%$, this work proves the impact of cycle aging on the available electric charge (capacity) at different state-of-charge values (SOC) by the help of impedance spectroscopy. During aging, the cell resistance grows and the pseudo-capacitance drops (Figure 9), and the imaginary part of impedance rises (Figure 5). For rapid impedance measurements, we propose a frequency around $0.2 \mathrm{~Hz}$. For practical use, the pseudo-capacitance according to Equation (4) best reflects the real state-of-charge (Figure 10). The imaginary part of impedance is less useful for SOC and SOH monitoring. Thanks to modern electronics, impedance measurements can be performed in airplanes throughout the pre-departure process with little expense and effort.

In addition, we found that pseudo-charge $Q(\omega)=C(\omega) \cdot U$ at $1 \mathrm{~Hz}$ is a proper measure for the real state-of-charge of a battery, where $U$ is the momentary voltage of battery at the time of impedance measurement. With this approach, there is no need for any model descriptions or equivalent circuits, which are often unclear and complicate the system analysis during operation. For SOH monitoring, the pseudo-charge of the aged battery with regard to the new battery is considered (Figure 8).

Author Contributions: Writing — original draft preparation, review and editing, P.K. and W.S. All authors have read and agreed to the published version of the manuscript.

Funding: This work was by supported by Diehl Aerospace GmbH. 
Conflicts of Interest: The authors declare no conflict of interest.

\section{References}

1. Kurzweil, P.; Shamonin, M. State-of-Charge Monitoring by Impedance Spectroscopy during Long-Term Self-Discharge of Supercapacitors and Lithium-Ion Batteries. Batteries 2018, 4, 35. [CrossRef]

2. Dubarry, M.; Truchot, C.; Liaw, B.Y. Synthesize battery degradation modes via a diagnostic and prognostic model. J. Power Sources 2012, 219, 204-216. [CrossRef]

3. Hammouche, A.; Karden, E.; De Doncker, R.W. Monitoring state-of-charge of Ni-MH and Ni-Cd batteries using impedance spectroscopy. J. Power Sources 2004, 127, 105-111. [CrossRef]

4. Xiong, R.; Cao, J.; Yu, Q.; He, H.; Sun, F. Critical Review on the Battery State of Charge Estimation Methods for Electric Vehicles. IEEE Access 2017, 6, 1832-1843. [CrossRef]

5. Sarmah, S.B.; Kalita, P.; Garg, A.; Niu, X.; Zhang, X.-W.; Peng, X.; Bhattacharjee, D. A Review of State of Health Estimation of Energy Storage Systems: Challenges and Possible Solutions for Futuristic Applications of Li-Ion Battery Packs in Electric Vehicles. J. Electrochem. Energy Convers. Storage 2019, 16, 040801. [CrossRef]

6. Zou, Y.; Hu, X.; Ma, H.; Li, S. Combined State of Charge and State of Health estimation over lithium-ion battery cell cycle lifespan for electric vehicles. J. Power Sources 2015, 273, 793-803. [CrossRef]

7. Rodrigues, S.; Munichandraiah, N.; Shukla, A.K. A review of state-of-charge indication of batteries by means of a.c. impedance measurements. J. Power Sources 2000, 87, 12-20. [CrossRef]

8. Bounaga, A. Device and Method for Measuring the Charge State of a Nickel-Cadmium Accumulator. U.S. Patent 5,650,937A, 22 July 1997.

9. Latner, N. Method for Determining the State of Charge of Nickel Cadmium Batteries by Measuring the Farad Capacitance Thereof. U.S. Patent 3,562,634A, 9 February 1971. Available online: https://worldwide.espacenet. $\mathrm{com} /$ searchResults?ST =singleline\&locale=de_EP\&submitted $=$ true\&DB=\&query $=\mathrm{US3562634}($ accessed on 8 January 2020).

10. Sathyanarayana, S.; Venugopalan, S.; Gopikanth, M.L. Impedance parameters and the state-of charge. I. Nickel-cadmium battery. J. Appl. Electrochem. 1979, 9, 125-139. [CrossRef]

11. Wenzl, H. Capacity. In Encyclopedia of Electrochemical Power Sources; Garche, J., Dyer, C.K., Moseley, P., Ogumi, Z., Rand, D., Scrosati, B., Eds.; Elsevier: Amsterdam, The Netherlands, 2009; Volume 1, pp. 395-400.

12. Waag, W.; Sauer, D.U. State-of-Charge/Health. In Encyclopedia of Electrochemical Power Sources; Garche, J., Dyer, C.K., Moseley, P., Ogumi, Z., Rand, D., Scrosati, B., Eds.; Elsevier: Amsterdam, The Netherlands, 2009; Volume 4, pp. 793-804.

13. Piller, S.; Perrin, M.; Jossen, A. Methods for state-of-charge determination and their applications. J. Power Sources 2001, 96, 113-120. [CrossRef]

14. Bergveld, H.J.; Danilov, D.; Notten, P.H.L.; Pop, V.; Regtien, P.P.L. Adaptive State-of-charge determination. In Encyclopedia of Electrochemical Power Sources; Garche, J., Dyer, C.K., Moseley, P., Ogumi, Z., Rand, D., Scrosati, B., Eds.; Elsevier: Amsterdam, The Netherlands, 2009; Volume 1, pp. 450-477.

15. Dowgiallo, E.J. Method for Determining Battery State of Charge by Measuring A.C. Electrical Phase Angle Change. U.S. Patent 3,984,762A, 5 October 1975.

16. Finger, E.P.; Sands, E.A. Method and Apparatus for Measuring the State of Charge of a Battery by Monitoring Reductions in Voltage. U.S. Patent 4,193,026A, 11 March 1978.

17. Kikuoka, T.; Yamamoto, H.; Sasaki, N.; Wakui, K.; Murakami, K.; Ohnishi, K.; Kawamura, G.; Noguchi, H.; Ukigaya, F. System for Measuring State of Charge of Storage Battery. U.S. Patent 4,377,787A, 22 March 1983.

18. Seyfang, G.R. Battery State of Charge Indicator. U.S. Patent 4,949,046, 14 August 1990.

19. Peled, E.; Yamin, H.; Reshef, I.; Kelrich, D.; Rozen, S. Method and Apparatus for Determining the State-of-Charge of Batteries Particularly Lithium Batteries. U.S. Patent 4,725,784A, 16 February 1988.

20. Hahn, M.; Schindler, S.; Triebs, L.C.; Danzer, M.A. Optimized Process Parameters for a Reproducible Distribution of Relaxation Times Analysis of Electrochemical Systems. Batteries 2019, 5, 43. [CrossRef]

21. Sato, Y.; Takeuchi, S.; Kobayakawa, K. Cause of the memory effect observed in alkaline secondary batteries using nickel electrode. J. Power Sources 2001, 93, 20-24. [CrossRef]

22. Linden, D.; Reddy, T.B. Handbook of Batteries; McGraw-Hill: New York, NY, USA, 2002.

23. Barsoukov, E.; Macdonald, J.R. Impedance Spectroscopy: Theory, Experiment, and Applications; John Wiley Sons: Hoboken, NJ, USA, 2018. 
24. Kurzweil, P.; Ober, J.; Wabner, D.W. Method for Correction and Analysis of Impedance Spectra. Electrochim. Acta 1989, 34, 1179-1185. [CrossRef]

25. Kurzweil, P.; Fischle, H.J. A new monitoring method for electrochemical aggregates by impedance spectroscopy. J. Power Sources 2004, 127, 331-340. [CrossRef]

26. Kurzweil, P.; Hildebrand, A.; Weiss, M. Accelerated Life Testing of Double-Layer Capacitors: Reliability and safety under Excess Voltage and Temperature. ChemElectroChem 2015, 2, 150-159. [CrossRef]

(C) 2020 by the authors. Licensee MDPI, Basel, Switzerland. This article is an open access article distributed under the terms and conditions of the Creative Commons Attribution (CC BY) license (http://creativecommons.org/licenses/by/4.0/). 